'Clap your hands' or 'take your hands'? One-year-olds distinguish between frequent and infrequent multiword phrases

\author{
Barbora Skarabela ${ }^{\mathrm{a}}$, Mitsuhiko Ota ${ }^{\mathrm{a}}$, Rosie O'Connor ${ }^{\mathrm{a}}$, and Inbal Arnon ${ }^{\mathrm{b}}$ \\ a School of Philosophy, Psychology and Language Sciences, University of Edinburgh \\ ${ }^{\mathrm{b}}$ Department of Psychology, Hebrew University of Jerusalem
}

Corresponding author:

Barbora Skarabela

University of Edinburgh

School of Philosophy, Psychology and Language Sciences

7 George Square

Edinburgh EH8 9AD

b.skarabela@ed.ac.uk 
INFANTS REPRESENT MULTIWORD INFORMATION

\begin{abstract}
Although words are often described as the basic building blocks of language, there is growing evidence that multiword sequences also play an integral role in language learning and processing. It is still not known, however, whether children become sensitive to multiword information at an age when they are still building knowledge of individual words. Using a central fixation paradigm, the present study examined whether infants between 11 and 12 months $(\mathrm{N}=36)$ distinguish between three-word sequences (trigrams) with similar substring frequencies but different multiword frequency in infant-directed speech (e.g., high frequency: 'clap your hands' vs. low frequency: 'take your hands'). Infants looked significantly longer at frequent trigrams compared to infrequent ones. This provides the first evidence that infants at the cusp of one-word production are already sensitive to the frequency of multiword sequences, and suggests they represent linguistic units of varying sizes from early on, raising the need to evaluate knowledge of both words and larger sequences during development.
\end{abstract}

Keywords: infants/children; multiword units; language learning; input 


\section{'Clap your hands' or 'take your hands'? One-year-olds distinguish between frequent and infrequent multiword phrases}

\section{Introduction}

While words are often considered the basic building blocks of language, recent work shows that multiword sequences also play an important role in language alongside individual words (see Arnon, in press; Christiansen \& Arnon, 2017 for reviews). This idea is found in linguistic approaches that emphasize the role of constructions (Culicover \& Jackendoff, 2005; Goldberg, 2006), and is advocated in single-system models of language where all linguistic material (from sounds, through words to multiword sequences) is processed by the same cognitive mechanisms (Bybee, 1998; Christiansen \& Chater, 2016; Elman, 2009; McClelland, 2010). Multiword units also play a prominent role in usage-based models of language learning where grammatical knowledge is learned by abstracting over stored exemplars of varying sizes and levels of abstraction (e.g., Abbot-Smith \& Tomasello, 2006; Bannard \& Lieven, 2012; McCauley \& Christiansen, 2019; Tomasello, 2003). Under such approaches, speakers are predicted to represent both words and multiword sequences.

Consistent with this prediction, there is evidence that speakers draw on multiword information in language learning, processing and use. Adults are sensitive to multiword frequency, with more frequent phrases recognized faster (Arnon \& Snider, 2010), remembered better (Tremblay, Derwing, Libben \& Westbury, 2011), and produced with shorter duration (Arnon \& Cohen Priva, 2013). These effects hold when controlling for all part frequencies, indicating knowledge about the frequency of the larger sequence. Furthermore, adults process three-word phrases acquired earlier during childhood faster than those that are acquired later, mirroring the well-documented Age-of-Acquisition effects for individual words and suggesting that multiword sequences also serve as units of learning (Arnon, McCauley \& Christiansen, 
INFANTS REPRESENT MULTIWORD INFORMATION

2017). These findings highlight the parallels between words and larger sequences and indicate that speakers represent both words and multiword units.

The evidence emerging from child language suggests that multiword information also influences children's production and processing. Four-year-olds are better at producing irregular plurals when they are part of a more frequent sequence (e.g., teeth in 'brush your teeth', Arnon \& Clark, 2011). Two- and three-year-olds are faster and more accurate in repeating higher frequency four-word phrases compared to lower frequency ones (e.g., 'sit in your chair' vs. 'sit in your truck', Bannard \& Matthews, 2008) and show faster recognition and better production of nouns when they are embedded in a familiar phrase ('where's the baby?' vs. 'the baby', Fernald \& Hurtado, 2006), or in more frequent bigrams (Jones, Cabiddu \& Avila-Varela, 2020). Many of children's early productions are 'frozen' or 'formulaic' multiword expressions (e.g., Lieven, Pine \& Barnes, 1992; Lieven, Behrens, Speares \& Tomasello, 2003; Lieven, Salomo \& Tomasello, 2009; Peters, 1983) and are better accommodated by a computational model that extracts both words and multiword units (McCauley \& Christiansen, 2019). Furthermore, production errors are related to children's knowledge of larger sequences that frequently occur in caregiver speech (e.g., Kirjavainen, Theakston \& Lieven, 2009). Taken together, these findings demonstrate that, like adult speakers, children represent multiword sequences as well as words.

However, the existing evidence leaves open an important theoretical question about how children come to learn multiword sequences. One possibility, in line with standard descriptions of language acquisition, is that children first learn individual words, and then begin to store information about their combinations. If true, sensitivity to multiword frequency should emerge only after children acquire substantial knowledge about words and their co-occurrence patterns. Alternatively, children could extract multiword sequences alongside and in parallel with individual words and represent both from the very start. This prediction is explicitly made 
INFANTS REPRESENT MULTIWORD INFORMATION

by the Starting Big approach to language learning (Arnon, 2010; Arnon \& Christiansen, 2017; Arnon, in press). Under this approach, children's initial linguistic inventory corresponds to prosodic boundaries, and consequently includes both word and multiword units, which serve an important role in learning grammatical relations (Arnon \& Ramscar, 2012; Siegelman \& Arnon, 2015). The prediction that young infants are not limited to individual words but also attend to larger sequences is consistent with the presence of frequent multiword combinations in child-directed speech (Cameron-Faulkner, Lieven, \& Tomasello, 2003) and with infants' early perceptual abilities: Infants show short-term memory of prosodically-coherent multiword strings early on (Mandel, Nelson, \& Jusczyk, 1996), and perceive the acoustic boundaries of larger units before smaller ones (e.g., utterance boundary before word boundary, Soderstrom, Seidl, Kemler Nelson \& Jusczyk, 2003).

Here, we go beyond existing findings and ask whether infants are sensitive to multiword frequency before they start producing multiword combinations, and when their productive and receptive vocabulary is still in its early stages. Such a finding would demonstrate that infants represent multiword information alongside words, underscoring their role in language acquisition, and opening up new questions about infants' initial linguistic inventory. Specifically, we ask whether 11- to 12-month-olds can distinguish between three-word sequences with similar plausibility and lexical frequency but different multiword frequency in infant-directed speech. At this age, English-learning children recognize some individual words and show awareness of formulaic expressions, such as 'peek-a-boo' or 'all gone' (Caselli, Bates, Casadio, Fenson, Fenson, Sanderl, \& Weir, 1995). However, there is currently no evidence that their knowledge extends to non-formulaic multiword sequences until around 18 months of age when they begin to produce two-word utterances (Bloom, 1993; GoldinMeadow \& Butcher, 2002). If infants already represent information about multiword sequences at the same time as they are learning words, we predict that 11- to 12-month-olds should 
INFANTS REPRESENT MULTIWORD INFORMATION

distinguish between multiword sequences that occur frequently in the input (e.g., 'clap your hands') and ones that are matched on lexical frequency but are infrequent in the input (e.g., 'take your hands'). We tested this prediction using an infant-controlled sequential looking procedure to measure infants' gaze fixation to a visual stimulus while they listened to frequent and infrequent three-word combinations (trigrams).

\section{Method}

\section{Participants}

Participants were 36 (18 females) typically developing 11- to 12-month-olds (Range: 335 to 377 days; Mean: 359 days). All infants were growing up in the U.K. in a monolingual or predominantly English-speaking family. They were all full-term births, and had no reported hearing problems. Five additional infants were tested but not included in the analysis due to fussiness/crying (3) or noncompletion (2).

\section{Materials}

\section{Trigram selection}

The test items consisted of pairs of three-word sequences that differed by one word (e.g., clap.your.hands - take.your.hands). In each pair, the sequences differed in trigram frequency (high vs. low), but were matched for substring frequency (i.e., each word, or unigram, and bigram). For example, clap.your.hands had a higher trigram frequency than take.your.hands, but clap and take were matched in frequency and so were clap.your and take.your. The items were constructed based on naturalistic British English infant-directed speech from the Nuffield corpus (McGillion, Pine, Herbert, \& Matthews, 2017) and the Edinburgh corpus (Ota, DaviesJenkins, \& Skarabela, 2018). Combined, they yielded a dataset of 363,081 words. The sampled caretaker speech was addressed to 11-month-olds in the Nuffield corpus and to 9- and 15month-olds in the Edinburgh corpus. Two criteria were used to select the initial set of trigrams: a) the high-frequency trigrams must occur at least 20 times per million in the corpus, which is 
INFANTS REPRESENT MULTIWORD INFORMATION

higher than the ten-per-million criteria often used to define high frequency in adult corpora (Arnon et al., 2017); and b) the substring frequencies between the high- and low-frequency trigrams must not differ by more than $20 \%$. The initial selection consisted of 19 pairs of trigrams that differed in only one word and could be construed as a constituent.

To assess their grammatical acceptability, we presented these trigrams to adult native speakers of English $(\mathrm{N}=24)$, together with 16 filler trigrams. Participants were asked to rate each word combination from 1 ('completely unacceptable, sounding bad in English') to 5 ('completely acceptable, sounding good in English'). The mean rating of these trigrams was $3.52(\mathrm{SD}=1.59)$. We selected 12 pairs of trigrams with the highest grammaticality ratings (mean $=4.67$, range: $4.0-5.0$ ). The frequent members of these pairs were on average 42.5 times more frequent than the infrequent members. The pairs did not differ significantly in substring frequency (all $t$ 's $<.1$ ) or grammaticality $(t=2.49, d f=22, p=.21$ ) (see Table 1 with summary unigram, bigram and trigram frequencies, and the Appendix B for frequency information for individual items).

Table 1. Mean frequencies per million words (and standard deviations) of trigrams and their substrings.

\begin{tabular}{llllllll}
\hline Condition & $\mathrm{N}$ & Trigram & Unigram1 & Unigram2 & Unigram3 & Bigram1 & Bigram2 \\
\hline Frequent & 12 & 39.1 & 1165.1 & 8251.5 & 970.1 & 186.4 & 149.8 \\
& $(17.2)$ & $(1265.4)$ & $(3238.9)$ & $(1370.0)$ & $(296.3)$ & $(149.8)$ \\
\hline Infrequent & 12 & 0.9 & 1136.1 & 8251.5 & 965.4 & 184.3 & 151.1 \\
& & $(2.3)$ & $(1259.3)$ & $(3238.9)$ & $(1372.2)$ & $(297.6)$ & $(149.9)$ \\
\hline
\end{tabular}

Note: UnigramN refers to the frequency of the Nth word (e.g., Unigram1 in 'clap your hands' is clap). BigramN refers to the frequency of the Nth two-word combination (e.g., Bigram1 in 'clap your hands' is clap.your). 
INFANTS REPRESENT MULTIWORD INFORMATION

\section{Auditory properties of the stimuli}

The trigrams were read by a female speaker of Southern British English using infantdirected speech. They were all produced with the same prosodic pattern marked by a low tone at the initial and final boundaries and a fall-rise nuclear pitch accent on the final word. All stimuli were normalized to $70 \mathrm{~dB}$, and the frequent and infrequent trigrams were comparable in their fundamental frequency (F0) measures and duration (see Table 2, all $t$ 's $<1$ ). The sound stimuli are available at https://osf.io/f6cgb/.

Table 2. Mean (and standard deviation) of mean F0, maximum F0, minimum F0 and duration of trigram stimuli in the frequent versus infrequent conditions.

\begin{tabular}{llllll}
\hline & $\mathrm{N}$ & F0 mean $(\mathrm{Hz})$ & $\mathrm{F} 0$ max $(\mathrm{Hz})$ & $\mathrm{F} 0$ min $(\mathrm{Hz})$ & Duration $(\mathrm{s})$ \\
\hline Frequent & 12 & $263(28)$ & $480(29)$ & $158(44)$ & $1.16(0.15)$ \\
\hline Infrequent & 12 & $274(31)$ & $500(52)$ & $147(45)$ & $1.19(0.11)$ \\
\hline
\end{tabular}

\section{Test sets}

For counterbalancing purposes, the 12 trigrams were divided into two lists, each with 6 frequent and 6 infrequent trigrams. Members of each pair (frequent/infrequent) were assigned to separate lists, A or B, so that a participant does not hear both. For example, Set A included the frequent variant clap.your.hands, and Set B included the infrequent variant take.your.hands. The lists did not significantly differ in whole-string or substring frequency (all $t$ 's $<1$, except $t=1.48, p=.16$ for bigram2 in Lists A \& B).

\section{Procedure}

The experiment was carried out in a dimly-lit sound-attenuated room, equipped with a 47-inch TV set to present the stimuli. Stimulus presentation was controlled by the Habit X 1.0 
INFANTS REPRESENT MULTIWORD INFORMATION

program (Cohen, Atkinson, \& Chaput, 2004). During the experiment, the infant sat on the caregiver's lap, seated approximately 1.5 meters away from the display monitor. The caregiver listened to masking music played over headphones, instructed not to speak to the infant or point at the monitor during the experiment. An experimenter in a separate room, with no access to the auditory stimuli played in the test room, recorded the infant's visual fixation to the monitor by observing their eye-gaze through a video camera located underneath the stimulus presentation monitor.

\section{Warm-up}

The experiment began with a warm-up phase when infants were presented with an animation sequence on the TV screen while listening to a classical piano piece for $18 \mathrm{~s}$. The animation was a green ball changing in size in the center of the screen, against a grey background. This was followed by an attention-getter sequence with animated bubbles moving toward the center of the screen and a background soundtrack of children's laughter. This sequence was also used to draw the infants' attention to the center of the screen between test trials.

\section{Test trial}

During test trials, the same green ball animation from the warm-up was shown with the auditory test stimuli. There were 6 frequent trigram trials and 6 infrequent trigram trials. In each trial, the participants heard either six different frequent trigrams or six different infrequent trigrams, played with a $2 \mathrm{~s}$ silence at the beginning and an inter-stimulus interval of $1.5 \mathrm{~s}$. For example, a participant would hear \{clap.your.hands, for.a.walk, sing.a.song, in.the.sky, open.it.up, yes.you.are $\}$ in the frequent trial and \{shake.it.off, turn.the.box, on.your.mouth, watch.your.boat, get.that.one, making.a.tower $\}$ in the infrequent trial. As explained above, the trigram pairs were counterbalanced across participants such that each participant heard only one of the variants from each pair (either the frequent or the infrequent trigram) and not both 
INFANTS REPRESENT MULTIWORD INFORMATION

members of the pair. The order of the trigrams within each trial was pseudorandomized. The trial ended when the infant looked away for 2 consecutive seconds. Otherwise, the trial lasted for $22 \mathrm{~s}$ (the length of the sound file). Trial order was pseudorandomized such that no condition (frequent vs. infrequent) was played more than twice in a row and each condition was played once during the first two trials of the experiment.

\section{Results}

The critical variable was the duration of central fixation in each trial. Following the standard procedure for this type of paradigm, the first trial for each individual child was excluded from the analysis (Cooper, Abraham, Berman, \& Staska, 1997; Shi \& Werker, 2001). Figure 1 displays the mean listening times for individuals and the grand means for the two conditions. On average, fixation times were longer for the frequent trigram trials (mean $=9.29 \mathrm{~s}$, $\mathrm{sd}=3.00$ ) than for the infrequent trigram trials (mean $=8.39 \mathrm{~s}, \mathrm{sd}=2.96$ ), exhibiting a familiarity effect which is typical of infant perception experiments without pre-exposure to stimuli (e.g., Houston-Price \& Nakai, 2004). This pattern was found individually in 23 out of the 36 infants. 


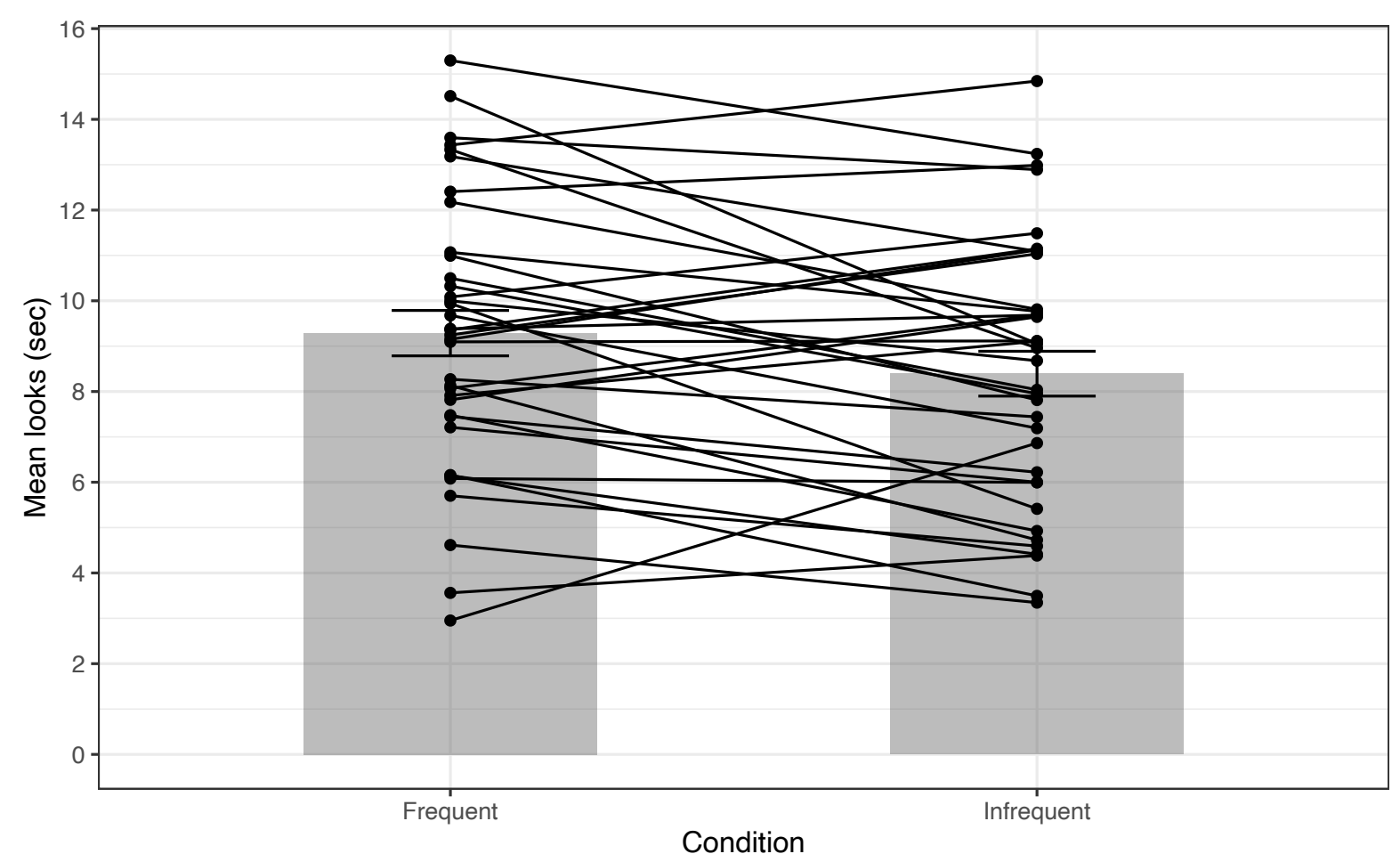

Figure 1. Mean looking times (seconds) by condition. Bars represent the mean and standard error per condition. Lines represent means of individual participants.

We conducted a linear mixed-effects analysis using the lmer function in R, with looking time as a dependent factor and condition (frequent vs. infrequent) as a fixed effect. Condition was sum-coded. The model also contained random intercepts and slopes for condition by individuals. There was a significant effect of condition (Estimate $=0.463, \mathrm{SE}=0.220, d f=$ 358.3, $t=2.103, p=0.0362$ ), confirming the observation that looking times were longer for frequent trigrams compared to infrequent trigrams. In order to explore the source of the individual differences, we carried out a follow-up analysis with age and gender included in the model along with their interactions with Condition. The results showed no effects of age or gender while Condition remained a significant factor.

\section{Discussion}

We set out to ask whether infants are sensitive to multiword information at an age when they are building up knowledge of individual words. Specifically, we examined whether 11- to 
INFANTS REPRESENT MULTIWORD INFORMATION

12-month-olds distinguish between three-word sequences that have similar plausibility and lexical frequency but differ in their multiword frequency in infant-directed speech. In an infantcontrolled sequential looking procedure, infants listened longer to frequent trigram trials than to infrequent trigram trials, suggesting that at this age they already represent multiword information. The results expand on previous findings that multiword information impacts language processing and learning in adults and older children (Lieven et al., 2003; Bannard \& Matthews, 2008; Arnon \& Clark, 2011), and provide the first evidence that infants are sensitive to the frequency of multiword sequences long before they begin producing such combinations.

The observed difference between frequent and infrequent trigrams could not be driven by the individual words, because the words distinguishing the frequent and infrequent trigrams (i.e., 'take' versus 'clap' in '_your hands') were matched for frequency (as were the bigrams). To show the effect, infants had to have stored the frequency of the entire sequence, indicating they attend to and represent larger sequences alongside words from early on, consistent with the predictions of the Starting Big approach (Arnon, 2010), and usage-based models more generally (e.g., Abbot-Smith \& Tomasello, 2006). The extraction of multiword sequences could be driven by infants' perceptual abilities: Segmenting speech according to prosodic boundaries will result in an initial inventory containing single words, sentence fragments and short multiword utterances, all of which can serve as building blocks for learning. This resonates with computational models of speech segmentation that often classify frequent multiword sequences as one word, even when they use only distributional cues: for instance, using transitional probabilities as a cue to word boundary yielded $30 \%$ of the proposed "words", which were in fact well-formed multiword sequences (Goldwater, Griffiths, \& Johnson, 2009; see also Swingley, 2005). That is, infants seem to extract linguistic units of varying sizes, raising the need to evaluate knowledge of both words and larger sequences during development. 
Importantly, our findings do not tell us whether infants represent the multiword sequences as unanalysed chunks or combinations of individually learned words. Given evidence that many of the words in the trigrams we used are not comprehended by infants at this age ${ }^{1}$, it is possible that at least some of the sequences, or parts of, were treated holistically as one lexical unit. Such a pattern is consistent with the presence of unsegmented or undersegmented chunks in children's early inventory (Peters, 1983; Arnon \& Christiansen, 2017; McCauley \& Christiansen, 2019). Whether or not a sequence is treated as one unit will be impacted by input statistics (McCauley \& Christiansen, 2019), as well as length, frequency, and other factors (Grimm, Cassani, Gillis, \& Daelemans, 2017; 2019). Under emergentist models of language (e.g., Bybee, 1995; McClelland, 2010; Arnon \& Snider, 2010), such holistic representations are expected to gradually lead to single word representations (as infants learn individual words), while still maintaining a multiword representation (tied to the individual words). Future work should examine the interplay between word and multiword representation by evaluating individual children's knowledge of the words making up the multiword sequences. Another area for future research is the effects of the syntactic structure on children's extraction of multiword sequences. The trigram variants in our study were complete syntactic constituents but the pairs were not fully matched on syntactic structure. This structural heterogeneity can be seen as an asset since it illustrates multiword sensitivity across different syntactic types (as has been found for adults, e.g., Arnon \& Priva, 2014). Nonetheless, further work could compare children's responses to structurally more homogeneous test examples to see if syntactic structure impacts the likelihood of extracting a multiword sequence.

\footnotetext{
${ }^{1}$ The 24 trigrams contained 40 unique words. Of these, 21 words could be found on the Words and Gestures form of the McArthur-Bates Communicative Development Inventory (CDI). According to normative CDI data accessed from Word bank (http://wordbank.stanford.edu/), on average only $17.6 \%$ of 11-month-olds understand these individual words.
} 
INFANTS REPRESENT MULTIWORD INFORMATION

Our results have further implications for how larger units could impact language acquisition more generally. Knowing how words co-occur can free up processing resources and help young children predict upcoming linguistic material: 18-month-olds, for instance, are faster at recognising nouns when embedded in familiar multiword sequences (e.g., 'Look at the doggie!', Fernald \& Hurtado, 2006), and show better learning of words that appear in more frequent bigrams (Jones et al., 2020). As proposed by usage-based approaches (e.g., AbbotSmith \& Tomasello, 2006; Arnon \& Clark, 2011), comparing multiword sequences to each other can also help children discover grammatical regularities, including inflection ('you walk' vs. 'you walked'). Furthermore, under the Starting Big Approach, multiword sequences may be critical in learning of semantically arbitrary relations between words, including gender marking and verb-preposition pairing (Arnon \& Christiansen, 2017). This idea is consistent with the observation that adult second language learners typically fail to acquire such relations because of their reliance on individual words instead of multiword combinations (Arnon, 2010, in press; Siegelman \& Arnon, 2015; Paul \& Gruter, 2016). The current finding provides support for the account's core prediction that the mastery of native language rests on multiword sequences as early units of learning.

Our study also supports the notion that language acquisition does not always progress from smaller to larger units but involves both part-to-whole and whole-to-part processes (Peters, 1977, 1983). Indeed, the presence of whole-to-part or big-to-small learning has been observed for other aspects of language acquisition. For example, there is evidence that phonological development involves learning sound patterns holistically at the word level rather than as a set of smaller phonological units (e.g., segments) (Ferguson \& Farwell, 1975; Vihman, 2017; Waterson, 1971). Similarly, a sizable portion of morphological development starts from inflected forms acquired as unanalysed units (or 'amalgams') before the underlying morphological units are identified (MacWhinney, 1978; Wilson, 2003). Our study adds to this 
INFANTS REPRESENT MULTIWORD INFORMATION

work and shows that children may learn individual words from multiword sequences (e.g., Arnon \& Clark, 2011; Theakston \& Lieven, 2017).

Finally, the results of this experiment offer evidence against a strict division between the lexicon and grammar with rules or constraints used to combine them (e.g., Pinker, 1999; Pinker \& Ullman, 2002). Under such dual-system accounts, frequency is not expected to impact forms generated by grammar, like the compositional trigrams we used as our test items. Instead, our findings are more compatible with single-system approaches to language, where speakers store and represent linguistic units of varying sizes and levels of abstraction (e.g., Bybee, 1995; McClelland, 2010; Tomasello, 2003), and where similar associative memory mechanisms impact the learning and processing of all linguistic experience (Arnon \& Snider, 2010; Tremblay \& Baayen, 2010). In this sense, the current study joins a growing literature questioning the qualitative division between 'stored' and 'computed' forms (e.g., Bybee, 1998; McClelland, 2010).

In conclusion, this is the first study to provide evidence for preverbal infants' sensitivity to multiword frequency. The ability to distinguish frequent and infrequent three-word sequences at this stage strongly suggests that infants build on linguistic material of various sizes and demonstrates that multiword sequences alongside individual words form an integral part of early language learning.

\section{Acknowledgements}

This research was in part supported by the School of Philosophy, Psychology and Language Sciences research fund awarded to Mitsuhiko Ota and by Israeli Science Foundation grant number 584/16 awarded to Inbal Arnon. We also thank the families who took part in the project with their children in the Wee Science Developmental Lab at the University of Edinburgh. 
INFANTS REPRESENT MULTIWORD INFORMATION

\section{References}

Abbot-Smith, K., \& Tomasello, M. (2006). Exemplar-learning and schematization in a usagebased account of syntactic acquisition. The Linguistic Review, 23(3). https://doi.org/10.1515/TLR.2006.011

Arnon, I. (2010). Starting big - the role of multi-word phrases in language learning and use. PhD Dissertation, Stanford University.

Arnon, I. (in press). The Starting Big Approach to language acquisition. Invited paper for special issue of Journal of Child Language: Theories in language acquisition, xx-xx.

Arnon, I., \& Christiansen, M. H. (2017). The role of multiword building blocks in explaining L1-L2 differences. Topics in Cognitive Science, 9(3), 621-636. https://doi.org/10.1111/tops.12271

Arnon, I., \& Clark, E. V. (2011). Why Brush your teeth is better than teeth - Children's word production is facilitated in familiar sentence-frames. Language Learning and Development, 7(2), 107-129. https://doi.org/10.1080/15475441.2010.505489

Arnon, I., \& Cohen Priva, U. (2013). More than words: The effect of multi-word frequency and constituency on phonetic duration. Language and speech, 56(3), 349-371.

Arnon, I., \& Cohen Priva, U. (2014). Time and again: The changing effect of word and multiword frequency on phonetic duration for highly frequent sequences. The Mental Lexicon, 9(3), 377-400.

Arnon, I., McCauley, S. M., \& Christiansen, M. H. (2017). Digging up the building blocks of language: Age-of-acquisition effects for multiword phrases. Journal of Memory and Language, 92, 265-280. https://doi.org/10.1016/j.jml.2016.07.004

Arnon, I., \& Ramscar, M. (2012). Granularity and the acquisition of grammatical gender: How order-of-acquisition affects what gets learned. Cognition, 122(3), 292-305. 
INFANTS REPRESENT MULTIWORD INFORMATION

Arnon, I., \& Snider, N. (2010). More than words: Frequency effects for multi-word phrases. Journal of Memory and Language, 62(1), 67-82.

https://doi.org/10.1016/j.jml.2009.09.005

Bannard, C., \& Lieven, E. (2012). Formulaic language in L1 acquisition. Annual Review of Applied Linguistics, 32, 3.

Bannard, C., \& Matthews, D. (2008). Stored word sequences in language learning: The effect of familiarity on children's repetition of four-word combinations. Psychological Science, 19(3), 241-248. https://doi.org/10.1111/j.1467-9280.2008.02075.x

Bloom, L. (1993). The transition from infancy to language: Acquiring the power of expression. Cambridge University Press.

Bybee, J. (1995). Regular morphology and the lexicon. Language and Cognitive Processes, 10(5), 425-455. https://doi.org/10.1080/01690969508407111

Bybee, J. (1998). A functionalist approach to grammar and its evolution. Evolution of Communication, 2(2), 249-278. https://doi.org/10.1075/eoc.2.2.06byb

Cameron-Faulkner, T., Lieven, E., \& Tomasello, M. (2003). A construction based analysis of child directed speech. Cognitive Science, 27(6), 843-873.

Caselli, M. C., Bates, E., Casadio, P., Fenson, J., Fenson, L., Sanderl, L., \& Weir, J. (1995). A cross-linguistic study of early lexical development. Cognitive Development, 10(2), 159-199.

Cohen, L., Atkinson, D. J., \& Chaput, H. H. (2004). Habit X: A new program for obtaining and organizing data in infant perception and cognition studies. University of Texas.

Cooper, R. P., Abraham, J., Berman, S., \& Staska, M. (1997). The development of infants' preference for motherese. Infant Behavior and Development, 20(4), 477-488. https://doi.org/10.1016/S0163-6383(97)90037-0 
INFANTS REPRESENT MULTIWORD INFORMATION

Christiansen, M. H., \& Arnon, I. (2017). More than words: The role of multiword sequences in language learning and use. Topics in Cognitive Science, 9(3), 542-551. https://doi.org/10.1111/tops. 12274

Christiansen, M. H., \& Chater, N. (2016). Creating language: Integrating evolution, acquisition, and processing. MIT Press.

Culicover, P. W., \& Jackendoff, R. (2005). Simpler syntax. Oxford University Press.

Elman, J. L. (2009). On the meaning of words and dinosaur bones: Lexical knowledge without a lexicon. Cognitive science, 33(4), 547-582.

Ferguson, C. A., \& Farwell, C. B. (1975). Words and sounds in early language acquisition. Language, 51(2), 419. https://doi.org/10.2307/412864

Fernald, A., \& Hurtado, N. (2006). Names in frames: Infants interpret words in sentence frames faster than words in isolation. Developmental Science, 9(3), F33-F40. https://doi.org/10.1111/j.1467-7687.2006.00482.x

Goldberg, A. E. (2006). Constructions at work: The nature of generalization in language. Oxford University Press.

Goldin-Meadow, S., \& Butcher, C. (2003). Pointing toward two-word speech in young children. In S. Kita (Ed.), Pointing: Where language, culture, and cognition meet (p. 85-107). Lawrence Erlbaum Associates Publishers.

Goldwater, S., Griffiths, T. L., \& Johnson, M. (2009). A Bayesian framework for word segmentation: Exploring the effects of context. Cognition, 112(1), 21-54.

Grimm, R., Cassani, G., Gillis, S., \& Daelemans, W. (2017). Facilitatory effects of multiword units in lexical processing and word learning: A computational investigation. Frontiers in Psychology, 8, 555. 
INFANTS REPRESENT MULTIWORD INFORMATION

Grimm, R., Cassani, G., Gillis, S., \& Daelemans, W. (2019). Children probably store short rather than frequent or predictable chunks: Quantitative evidence from a corpus study. Frontiers in Psychology, 10, 80. https://doi.org/10.3389/fpsyg.2019.00080

Houston-Price, C., \& Nakai, S. (2004). Distinguishing novelty and familiarity effects in infant preference procedures. Infant and Child Development: An International Journal of Research and Practice, 13(4), 341-348.

Jones, G., Cabiddu, F., \& Avila-Varela, D. S. (2020). Two-year-old children's processing of two-word sequences occurring 19 or more times per million and their influence on subsequent word learning. Journal of Experimental Child Psychology, 199, 104922.

Kirjavainen, M., Theakston, A., \& Lieven, E. (2009). Can input explain children's me-for-I errors? Journal of Child Language, 36(5), 1091-1114.

Lieven, E., Behrens, H., Speares, J., \& Tomasello, M. (2003). Early syntactic creativity: A usage-based approach. Journal of Child Language, 30(2), 333-370. https://doi.org/10.1017/S0305000903005592

Lieven, E., Salomo, D., \& Tomasello, M. (2009). Two-year-old children's production of multiword utterances: A usage-based analysis. Cognitive Linguistics, 20(3). https://doi.org/10.1515/COGL.2009.022

Lieven, E. V. M., Pine, J. M., \& Barnes, H. D. (1992). Individual differences in early vocabulary development: Redefining the referential-expressive distinction. Journal of Child Language, 19(2), 287-310. https://doi.org/10.1017/S0305000900011429

MacWhinney, B. (1978). The acquisition of morphophonology. Monographs of the Society for Research in Child Development, 43(1/2), 1. https://doi.org/10.2307/1166047

Mandel, D. R., Nelson, D. G. K., \& Jusczyk, P. W. (1996). Infants remember the order of words in a spoken sentence. Cognitive development, 11(2), 181-196. 
INFANTS REPRESENT MULTIWORD INFORMATION

McCauley, S. M., \& Christiansen, M. H. (2019). Language learning as language use: A crosslinguistic model of child language development. Psychological Review, 126(1), 1-51. https://doi.org/10.1037/rev0000126

McClelland, J. L. (2010). Emergence in cognitive science. Topics in Cognitive Science, 2(4), 751-770. https://doi.org/10.1111/j.1756-8765.2010.01116.x

McGillion, M., Pine, J. M., Herbert, J. S., \& Matthews, D. (2017). A randomised controlled trial to test the effect of promoting caregiver contingent talk on language development in infants from diverse socioeconomic status backgrounds. Journal of Child Psychology and Psychiatry, 58(10), 1122-1131.

Ota, M., Davies-Jenkins, N., \& Skarabela, B. (2018). Why choo-choo is better than train: The role of register-specific words in early vocabulary growth. Cognitive Science, 42(6), 1974-1999. https://doi.org/10.1111/cogs.12628

Paul, J. Z., \& Grüter, T. (2016). Blocking effects in the learning of Chinese classifiers. Language Learning, 66(4), 972-999.

Peters, A. M. (1977). Language learning strategies: Does the whole equal the sum of the parts? Language, 53(3), 560. https://doi.org/10.2307/413177

Peters, A. M. (1983). The units of language acquisition. Cambridge University Press.

Pinker, S. (1999). Words and rules: The ingredients of language (1st ed). Basic Books.

Pinker, S., \& Ullman, M. T. (2002). The past and future of the past tense. Trends in Cognitive Sciences, 6(11), 456-463. https://doi.org/10.1016/S1364-6613(02)01990-3

Shi, R., \& Werker, J. F. (2001). Six-month-old infants' preference for lexical words. Psychological Science, 12(1), 70-75. https://doi.org/10.1111/1467-9280.00312

Siegelman, N., \& Arnon, I. (2015). The advantage of starting big: Learning from unsegmented input facilitates mastery of grammatical gender in an artificial language. Journal of Memory and Language, 85, 60-75. 
INFANTS REPRESENT MULTIWORD INFORMATION

Soderstrom, M., Seidl, A., Nelson, D. G. K., \& Jusczyk, P. W. (2003). The prosodic bootstrapping of phrases: Evidence from prelinguistic infants. Journal of Memory and Language, 49(2), 249-267.

Swingley, D. (2005). Statistical clustering and the contents of the infant vocabulary. Cognitive psychology, 50(1), 86-132.

Theakston, A., \& Lieven, E. (2017). Multiunit sequences in first language acquisition. Topics in Cognitive Science, 9(3), 588-603. https://doi.org/10.1111/tops.12268

Tomasello, M. (2003). Constructing a language: A usage-based theory of language acquisition. Harvard University Press.

Tremblay, A., \& Baayen, H. (2010). Holistic processing of regular four-word sequences: A behavioral and ERP study of the effects of structure, frequency, and probability on immediate free recall. In D. Wood (Ed.), Perspectives on formulaic language: Acquisition and communication (pp. 151-173). Continuum.

Tremblay, A., Derwing, B., Libben, G., \& Westbury, C. (2011). Processing advantages of lexical bundles: Evidence from self-paced reading and sentence recall tasks. Language learning, 61(2), 569-613.

Vihman, M. M. (2017). Learning words and learning sounds: Advances in language development. British Journal of Psychology, 108(1), 1-27. https://doi.org/10.1111/bjop.12207

Waterson, N. (1971). Child phonology: A prosodic view. Journal of Linguistics, 7(2), 179211. https://doi.org/10.1017/S0022226700002917

Wilson, S. (2003). Lexically specific constructions in the acquisition of inflection in English. Journal of Child Language, 30(1), 75-115. https://doi.org/10.1017/S0305000902005512 
INFANTS REPRESENT MULTIWORD INFORMATION

\section{Appendix A}

Supplementary information

The data of this study are publicly available via the Open Science Framework (https://osf.io/f6cgb/). 
INFANTS REPRESENT MULTIWORD INFORMATION

\section{Appendix B}

\section{List of trigrams}

\begin{tabular}{|c|c|c|c|c|c|c|c|c|c|c|c|c|c|c|}
\hline Pair & Trigram & Fruequency & Bigram1 & B1.freq & Bigram2 & B2.freq & Onigram1 & U1.freq & Unigram2 & U2.freq & Unigram3 & U3.freq & Set & Condition \\
\hline 1 & take.it.off & 29 & take.it & 79 & it.off & 89 & take & 443 & it & 8178 & off & 780 & B & Freq \\
\hline 1 & shake.it.off & 0 & shake.it & 67 & it.off & 89 & shake & 455 & it & 8178 & off & 780 & A & Infreq \\
\hline 2 & clap.your.hands & 55 & clap.your & 60 & your.hands & 148 & clap & 552 & your & 5010 & hands & 302 & A & Freq \\
\hline 2 & take.your.hands & 0 & take.your & 62 & your.hands & 148 & take & 443 & your & 5010 & hands & 302 & B & Infreq \\
\hline 3 & turn.the.box & 0 & turn.the & 98 & the.box & 99 & turn & 302 & the & 10261 & box & 218 & A & Infreq \\
\hline 4 & for.a.walk & 35 & for.a & 244 & a.walk & 42 & for & 1890 & $\mathrm{a}$ & 8147 & walk & 123 & A & Freq \\
\hline 4 & for.a.cow & 0 & for.a & 244 & a.cow & 39 & for & 1890 & $\mathrm{a}$ & 8147 & cow & 120 & B & Infreq \\
\hline 5 & sing.a.song & 21 & sing.a & 26 & a.song & 46 & sing & 82 & $\mathrm{a}$ & 8147 & song & 99 & A & Freq \\
\hline 5 & thats.a.song & 0 & thats.a & 22 & a.song & 46 & thats & 88 & $\mathrm{a}$ & 8147 & song & 99 & B & Infreq \\
\hline 6 & in.the.sky & 32 & in.the & 1079 & the.sky & 49 & in & 3260 & the & 10261 & sky & 64 & A & Freq \\
\hline 6 & in.the.end & 1 & in.the & 1079 & the.end & 50 & in & 3260 & the & 10261 & end & 64 & B & Infreq \\
\hline 7 & yes.you.are & 38 & yes.you & 75 & you.are & 293 & yes & 948 & you & 16661 & are & 3836 & A & Freq \\
\hline 7 & so.you.are & 0 & so.you & 89 & you.are & 293 & so & 1115 & you & 16661 & are & 3836 & B & Infreq \\
\hline 8 & on.your.head & 54 & on.your & 346 & your.head & 156 & on & 3524 & your & 5010 & head & 372 & B & Freq \\
\hline 8 & on.your.mouth & 1 & on.your & 346 & your.mouth & 168 & on & 3524 & your & 5010 & mouth & 305 & A & Infreq \\
\hline
\end{tabular}




\section{INFANTS REPRESENT MULTIWORD INFORMATION}

\begin{tabular}{|c|c|c|c|c|c|c|c|c|c|c|c|c|c|}
\hline want.that.one & 22 & want.that & 68 & that.one & 560 & want & 2377 & that & 6008 & one & 3364 & B & Freq \\
\hline get.that.one & 8 & get.that & 80 & that.one & 560 & get & 2122 & that & 6008 & one & 3364 & A & Infreq \\
\hline build.a.tower & 32 & build.a & 46 & a.tower & 57 & build & 139 & $\mathrm{a}$ & 8147 & tower & 164 & B & Freq \\
\hline making.a.tower & 1 & making.a & 39 & a.tower & 57 & making & 112 & $\mathrm{a}$ & 8147 & tower & 164 & A & Infreq \\
\hline row.your.boat & 49 & row.your & 50 & your.boat & 63 & row & 167 & your & 5010 & boat & 106 & B & Freq \\
\hline open.it.up & 23 & open.it & 66 & it.up & 201 & open & 297 & it & 8178 & up & 2227 & A & Freq \\
\hline leave.it.up & 0 & leave.it & 42 & it.up & 201 & leave & 159 & it & 8178 & up & 2227 & B & Infreq \\
\hline
\end{tabular}

